\title{
Identifikasi Koefisien Atenuasi dan Implementasinya Untuk Mengetahui Kesiapsiagaan Masyarakat Terhadap Bencana Gempa Bumi di Kota Bengkulu
}

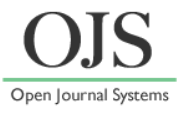

\author{
Fitriana $^{1 *}$, Muhammad Farid ${ }^{2}$, Afrizal Mayub ${ }^{1}$, Connie $^{3}$ \\ ${ }^{1}$ Pascasarjana Pendidikan IPA FKIP Universitas Bengkulu \\ ${ }^{2}$ Jurusan Fisika FMIPA Universitas Bengkulu \\ ${ }^{3}$ Pendidikan Fisika FKIP Universitas Bengkulu \\ *Email: fitriana090510@gmail.com
}

DOI: https://doi.org/10.33369/pendipa.v3i1.6921

\begin{abstract}
[Identification of Attenuation Coefficient and the Implementation to Know People Preparedness on Earthquake Disasters in Bengkulu City]. This study aims to identify attenuation coefficients against sediment susceptibility during an earthquake in the city of Bengkulu and map out hazardous areas during an earthquake based on attenuation coefficient values and its implementation to find out about community preparedness, and who live in earthquake-prone areas of the impact of the earthquake. This research was conducted with the method of field data collection in the Beringin Raya sub-district and the Kandang Limun village in the city of Bengkulu in the form of seismic micro data using a 3 component short-circuit seismometer. From 20 research points, the regions that have the highest attenuation coefficient are obtained at the coordinate point S: $-3.75625 \mathrm{E}: 102.2952222$ and $S:-3.75625 \mathrm{E}$ : 102.2697778 which is 1.6x10-2. Mapping based on coefficient values at each point using ArcGIS 10.3 Software. As for educational / social research, the method used in community education / social research is to use a quantitative approach with descriptive methods. The population in this study were all family heads in the Beringin Raya sub-district and Kandang Limun village. The sampling technique is simple random sampling. Data collection techniques using questionnaire techniques. The questionnaire analysis technique uses the correlation of the Produc Moment formula. Requirements for test analysis are carried out by testing empirical validity and reliability testing. the average community in Kelingin Beringin Raya and Keluran Kandang Limun is in the category of almost ready to deal with earthquake disasters, namely 47.14\%. So that it still desperately needs knowledge about earthquake disasters.
\end{abstract}

Keywords: Atenuation; coefficient; preparedness; earthquake; disaster.

(Received April 20, 2018; Accepted December 10, 2018; Published February 26, 2019)

\begin{abstract}
ABSTRAK
Penelitian ini bertujuan untuk mengidentifikasi koefisien atenuasi terhadap kerentanan sedimen saat terjadi gempa bumi di kota Bengkulu dan memetakan area berbahaya saat terjadinya gempa berdasarkan nilai koefisien atenuasi. Serta implementasinya untuk mengetahui kesiapsiagaan masyaraka. yang bertempat tinggal di daerah rawan gempa bumi terhadap dampak gempa. Penelitian ini dilakukan dengan metode pengambilan data lapangan di kelurahan Beringin Raya dan kelurahan Kandang Limun Kota Bengkulu berupa data mikro seismik menggunakan alat seismometer arus pendek 3 komponen. Dari 20 titik penelitian maka diperoleh daerah yang memiliki nilai koefisien atenuasi tertinggi yaitu di titik koordinat S:-3.75625 E: 102.2952222 dan S: -3.75625 E: 102.2697778 yaitu sebesar 1,6x10 ${ }^{-2}$. Pemetaan bedasarkan nilai koefien setiap titik menggunakan Software ArcGIS 10.3. Sedangkan untuk penelitian pendidikan/sosial masyarakat, metode yang digunakan adalah menggunakan pendekatan kuantitatif dengan metode deskriptif. Populasi dalam penelitian ini adalah seluruh kepala keluarga yang ada di kelurahan Beringin Raya dan kelurahan Kandang Limun. Teknik pengambilan sampel adalah simple random sampling. Teknik pengumpulan data menggunakan teknik angket. Teknik analisa butir angket menggunaka korelasi rumus Produc Moment. Persyaratan uji analisis dilakukan dengan uji validitas
\end{abstract}


empiris dan uji reliabilitas. rata-rata masyarakat di Keluran Beringin Raya dan Keluran Kandang Limun tergolong pada kategori hampir siap dalam menghadapi bencana gempa bumi yaitu dengan persentase $47,14 \%$. Sehingga masih sangat membutuhkan pengetahuan tentang bencana gempa bumi.

Kata kunci: Koefisien; atenuasi; kesiapsiagaan; bencana; gempa bumi.

\section{PENDAHULUAN}

Secara geografis Kota Bengkulu terletak di tepi pantai barat Sumatra dengan posisi $102^{0} 14 "-102^{0} 22 "$ BT dan $3^{0} 45^{\prime \prime}-3^{0} 59^{\prime \prime}$ LS. Berdasarkan peta Geology Of Indonesia yang diterbitkan oleh U.S GEOLOGICAL SURVEY 1965 geologi dan morfologi wilayah Bengkulu (termasuk di dalamnya kota Bengkulu). Kota Bengkulu merupakan salah satu daerah di Indonesia yang sering mengalami gempa bumi.

Gempa bumi adalah salah satu fenomena alam dalam bentuk guncangan tanah yang dapat menyebabkan kerusakan pada alam, infrastruktur, dan membahayakan nyawa manusia. Seberapa besar kemungkinan kerusakan yang terjadi pada suatu daerah yang khususnya daerah sedimentasi, sangat dipengaruhi oleh kekuatan tanah yang merupakan medium perambatan gelombang gempa bumi tersebut. Kerentanan tanah atau sedimentasi terhadap gelombang gempa bumi dapat dilihat dari jenis tanah tersebut. Tanah atau batuan yang keras maka nilai koefisien atenuasinya kecil, jika tanah tersebut lunak maka nilai koefisien atenuasinya besar, Artinya gelombang seismik akan semakin mudah diteruskan ketika melewati batuan yang keras dan sebalik-nya akan lebih sulit diteruskan ketika melewati batuan yang lunak. Atenuasi (redaman) gelombang adalah proses pengurangan energi gelombang akibat penyerapan dan penyebaran selama penjalaran di dalam medium (Sengara dkk, 2006).

Perlunya dilakukan identifikasi koefisien atenuasi untuk daerah kota bengkulu, agar dapat diketahui daerah-daerah yang memiliki jenis tanah yang keras atau yang lunak. Jika nilai koefisien atenuasi sedimen atau batuan di suatu daerah besar maka kerentanan sedimen terhadap gempa bumi tinggi atau daerah tersebut berbahaya ketika terjadi gempa bumi, dan sebaliknya jika nilai koefisien atenuasi sedimen yang diperoleh kecil maka daerah tersebut merupakan daerah dengan resiko lebih kecil ketika terjadi gempa bumi. Implementasi dari hasil penelitian ini kemudian digunakan untuk penelitian pendidikan. Hasil dari penelitian sains yang berupa peta daerah berbahaya saat terjadi gempa bumi digunakan sebagai acuan penelitian Pendidikan / sosial masyarakat. Penelitian ini dilakukan untuk mengetahui kesiapasiagaan masyaraka kota Bengkulu yang berada di daerah berbahaya saat terjadi gempa bumi di Kota Bengkulu.

\section{LANDASAN TEORI}

\section{Koefisien Atenuasi}

Penentuan nilai Q-faktor didasarkan pada analisis grafik hubungan antara puncak-puncak suatu event gempa dengan waktu kejadiannya $(t)$. Waktu tempuh gelombang bergantung pada sumber gempa berasal. Secara umum, Q-faktor meningkat seiring dengan membesarnya densitas suatu material (batuan) dan juga kecepatan intrinsi batuan atau cepat rambat sinyal seismic batuan tersebut (Sherrif dan Geldart, 1955 dalam Ernawati 2011).

Didalam kajian ilmu teknik, atenuasi biasanya diukur dalam satuan desibel persatuan panjang medium (kabel, tembaga, udara, air, serat optik, dan sebagainya) maka satuan dari atenuasi sering dituliskan $\mathrm{dB} / \mathrm{cm}$ atau $\mathrm{dB} / \mathrm{km}$. Atenuasi yang diukur dalam penelitian ini adalah atenuasi dari rekaman gelombang seismic yang berupa gelombang sinusoidal, maka satuan dari atenuasi gelombang dapat dituliskan $\mathrm{dB} / \lambda . \lambda$ merupakan simbol untuk panjang gelombang dalam SI meter (m). Satuan atenuasi rekaman gelombang seismik adalah desibel persatuan panjang gelombang (Ernawati, 2011).

Persamaan koefisien atenuasi $(\alpha)$ sbb:

$$
\begin{gathered}
\alpha=\frac{\pi\left(\mathrm{f}_{2}-\mathrm{f}_{1}\right)}{V_{\mathrm{p}}} \\
V_{p}=1,6 \times V_{s}+1,36
\end{gathered}
$$

Keterangan :

$\alpha=$ koefisien atenuasi 
$v_{\mathrm{p}}=$ kecepatan gelombang primer

$v_{\mathrm{s}}=$ kecepatan gelombang skunder

$$
f_{1} \& f_{2}=\text { frekunsi }
$$

Harga $v_{p}$ akan semakin besar seiring dengan kekerasan batuan, sehingga semakin keras suatu batuan maka akan semakin kecil harga $\alpha$.

\section{Kesiapsiagaan Masyarakat Terhadap Bencana Gempa Bumi}

Menurut Jan Sopaheluwakan (2006) tingkat kesiapsiagaan masyarakat dapat dikategorikan menjadi lima diantaranya: Sangat Siap, Siap, Hampir Siap, Kurang Siap, Tidak Siap. Kesiapsiagaan didefiniskan sebagai tindakan atau aktivitas yang dilakukan sebelum suatu bencana terjadi. Kesiapsiagaan menurut Gregg dkk (2004), bertujuan untuk memastikan bahwa sumber daya yang diperlukan untuk tanggap dalam peristiwa bencana dapat digunakan secara efektif pada saat bencana dan tahu bagaimana menggunakanya (Sutton dan Tierney, 2006). Kesiapsiagaan akan membuat masyarakat mempertimbangkan berbagai hal dalam melakukan segala tindakan mereka sehingga tidak berisiko terkena dampak bencana (Zhai dkk, 2005). Dengan indikator sebagai berikut: Mengetahui kesiapsiagaan masyarakat saat terjadi gempa bumi. Pengetahuan masyarakat tentang bencana alam, tipe-tipe kejadian alam yang menimbulkan bencana, penyebab, ciri-ciri dan tindakan penyelamatan saat terjadi bencana. Motivasi keluarga untuk kesiapsiagaan dalam mengenali kejadian alam yang menimbulkan bencana. Ketersediaan peralatan cadangan bila terjadi keadaan darurat. Antisipasi yang masyarakat lakukan untuk meminimalisir kerugian akibat gempa bumi.

Kota Bengkulu

Bentuk wilayah Kota Bengkulu memanjang dari utara ke selatan dan sejajar dengan pantai, oleh karena itu, agar semua wilayah dapat terwakili maka dipilih 3 sektor, yaitu sektor utara, tengah dan selatan. Sektor utara diwakili oleh Kecamatan Muara Bangkahulu, sektor tengah Kecamatan Ratu Agung dan Gading Cempaka. Sedangkan sektor selatan diwakili Kecamatan Kampung Melayu dan Selebar. Kemudian di tiap sektor tersebut dibagi 3 zona wilayah, yaitu : (1) wilayah dekat pantai (berbatasan dengan pantai) disebut zona dekat/ rawan tsunami; (2) wilayah yang jarak dari pantai sedang disebut zona sedang/ hatihati; dan (3) wilayah yang jauh dari pantai disebut zona jauh/ aman tsunami. Pembagian tiga zona tersebut mempertimbangkan hal-hal sebagai berikut : 1. Jarak wilayah dari pantai. 2. Zona-zona tingkat resiko kegempaan Kota Bengkulu dari Peta Kajian Bahaya yang dibuat Puslitbang Geologi Dep.ESDM, Bandung (2005). 3. Hasil diskusi dengan beberapa narasumber dari Universitas Bengkulu. 4. Observasi langsung di lapangan. Masing-masing sektor dan zona tersebut diwakili satu kelurahan, bilamana jumlah rumah tangga yang ditargetkan menjadi sampel jumlahnya terpenuhi. Namun apabila jumlah rumah tangga yang ditargetkan menjadi sampel dalam satu kelurahan tersebut tidak terpenuhi, maka perlu ditambah satu kelurahan terdekat dengan syarat yang kondisi geografisnya kurang lebih sama (LIPI UNESCO/ISDR, 2006).

\section{Skala Likert}

Skala Likert ialah skala yang dapat dipergunakan untuk mengukur sikap, pendapat, dan persepsi seseorang atau sekelompok orang tentang suatu gejala atau fenomena pendidikan. Skala Likert adalah suatu skala psikometrik yang umum digunakan dalam kuesioner, dan merupakan skala yang paling banyak digunakan dalam riset berupa survei. Nama skala ini diambil dari nama Rensis Likert, pendidik dan ahli psikolog Amerika Serikat. Rensis Likert telah mengembangkan sebuah skala untuk mengukur sikap masyarakat di tahun 1932.

Skala itu sendiri salah satu artinya, sekedar memudahkan, adalah ukuran-ukuran berjenjang. Skala penilaian, misalnya, merupakan skala untuk menilai sesuatu yang pilihannya berjenjang, misalnya $0,1,2,3,4,5$, $6,7,8,9,10$. Skala Likert juga merupakan alat untuk mengukur (mengumpulkan data dengan cara "mengukur menimbang") yang "itemnya" (butir-butir pertanyaannya) berisikan (memuat) pilihan yang berjenjang.

Skala Likert digunakan untuk mengukur sikap, pendapat, dan persepsi seseorang atau sekelompok orang tentang fenomena sosial. Dengan Skala Likert, variabel yang akan diukur dijabarkan menjadi indikator variabel. Kemudian indikator tersebut dijadikan sebagai 
titik tolak untuk menyusun item-item instrumen yang dapat berupa pertanyaan atau pernyataan. Jawaban setiap item instrumen yang menggunakan Skala Likert mempunyai gradasi dari sangat positif sampai sangat negatif.

\section{METODE PENELITIAN}

Peneliti mengambil data langsung kelapangan. Daerah-daerah pengambilan data tersebut yaitu di dua Kelurahan di kota Bengkulu yaitu Kelurahan Beringin Raya dan Kecamata Kandang Limun kota Bengkulu. Pengambilan data dilakukan pada 20 titik dengan menggunakan alat seismometer portable short periode tipe pendek 3 komponen. Titiktitik pengambilan data di rencanakan akan dilakukan 5 titik di Kelurahan Beringin Raya dan 5 titik di Kelurahan Kandang Limun. Titik ke-1 di Sungai Hitam, titik ke-2 Unib Depan, titik ke-3 di Depan Gedung C, titik ke-4 depan Pom Bensin, titik ke-5 di Mess UNIB. Titik ke-6 depan GB.3, titik ke-7 di Gang 3, titik-8 Lapangan Kandang Limun, titik ke-9 di Gang Melati, titik ke-10 di Gang Juwita. Data yang diperoleh selanjutnya akan dianalisis dengan persamaan 2.2.1, dari analisis tersebut dapat diidentifikasi besar-kecilnya nilai koefisien atenuasi di setiap titik. Nilai-nilai koefisien tersebut selanjutnya akan diolah dengan Software ArcGIS10.3 dengan output berupa peta daerah yang berbahaya saat terjadi gempa bumi.

Metode yang digunakan dalam penelitian pendidikan/sosial masyarakat adalah menggunakan pendekatan kuantitatif dengan metode deskriptif di dalam indeks tersebut meliputi parameter yaitu pengetahuan dan sikap. Populasi dalam penelitian ini adalah seluruh kepala keluarga yang ada di Kelurahan Beringin Raya dan Kelurahan Kandang Limun Kota Bengkulu. Mengambil sampel dengan teknik pengambilan sampel adalah simple random sampling. Teknik pengumpulan data menggunakan teknik angket. Teknik analisa data yang digunakan adalah metode deskriptif kuantitatif melalui scoring. Persyaratan uji analisis dilakukan dengan uji validitas dan uji reliabilitas.

Populasi dari penelitian pendidikan/sosial masyarakat adalah seluruh kepala keluarga yang ada di Kelurahan beringin raya dan Kelurahan kandang limun kota bengkulu. Berdasarkan data hasil observasi ke masing-masing kelurahan. Didapat data jumlah kepala keluarga dikelurahan kandang limun adalah 1401 KK dan jumlah kepala keluarga di kelurahan beringin raya 457 KK. Melalui teknik simple random sampling maka di dapat 70 sampel untuk penelitian ini.

Uji validitas Empiris adalah sebuah instrument yang menunjukan pada kondisi yang telah diuji dari pengalaman (Arikunto, 2002). Instrument ini digunakan mengetahui kesiapsiagaan masyarakat Kota Bengkulu dalam menghadapi bahaya gempa bumi di daerah rawan gempa bumi menggunakan statistik Product Moment,

$r_{x y}=\frac{N \sum X Y-\left(\sum X\right)\left(\sum Y\right)}{\left.\sqrt{\left\{N X^{2}\right.}-\left(\sum X\right)^{2}\right\}\left\{N \sum^{2}-\left(\sum Y\right)^{2}\right\}}$

Keterangan :

$r_{x y}=$ koefisien korelasi butir

$\sum \mathrm{X}=$ jumlah skor tiap item

$\sum \mathrm{Y}=$ jumlah skor total item

$\sum X^{2}=$ jumlah skor-skor $X$ yang dikuadratkan

$\sum Y^{2}=$ jumlah skor-skor $Y$ yang dikuadratkan

$\sum X Y=$ jumlah perkalian $X$ dan $Y$

$\mathrm{N}=$ jumlah sample

Hasil perhitungan dibandingkan dengan tabel product moment. Jika $\mathrm{r}_{\text {hitung }}$ lebih besar dari $r_{\text {tabel }}$ maka butir kuesioner tersebut dapat dinyatakan valid. Uji Reliabilitas menggunakan rumus Alpha Cronbach sebagai berikut:

$r_{11}=\left[\frac{k}{k-1}\right]\left[1-\frac{\sum \sigma i^{2}}{\sigma t^{2}}\right]$

Dimana $: r_{11}:$ reliabilitas instrumen

$k \quad$ : banyak butir pertanyaan atau banyanya soal

$\sum \sigma_{n}^{2}:$ jumlah varian butir

$\sigma_{t}^{2} \quad$ : varian total

Data yang digunakan dalam penelitian ini adalah data data kuesioner, data tersebut digunakan untuk mengukur tingkat kesiapsiagaan masyarakat terhadap bencana gempa bumi. Responden dalam penelitian ini sebanyak 70 kepala keluarga, dan jumlah butir pernyataan yang digunakan dalam kuesioner sebanyak 29 butir. Analisisnya berupa frekuensi (banyaknya) atau proporsinya (persentase). 
Menghitung persentase item tiap jawaban dari angket yaitu:

$$
\frac{\text { jumlah jawaban } 1 \text { item }}{\text { jumlah responden }} \times 100 \%
$$

\section{HASIL DAN PEMBAHASAN}

\section{Koefisien Atenuasi}

Data penelitian sains telah diambil di 20 titik penelitian yaitu dari titik koordinat S:3.75625 E:102.2685833 sampai titik koordinat S:-3.75625 E: 102.2745833. Dari 20 titik penelitian maka diperoleh daerah yang memiliki nilai koefisien atenuasi tertinggi berada pada koordinat S:-3.75625 E: 102.2952222 dan S: $3.75625 \mathrm{E}: 102.2697778$ yaitu sebesar $1,6 \times 10^{-2}$. Berdasarkan hasil analisis aplikasi geopsy maka di peroleh sepectrum seismic seperti Gambar 1.
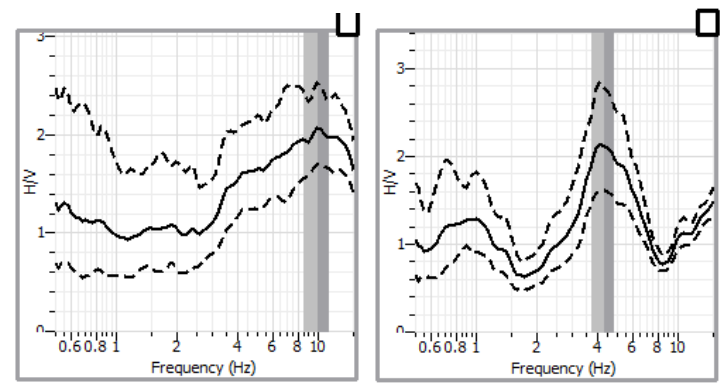

Gambar 1. Spektrum seimik lokasi penelitian 12 dan 19

Berdasarkan data hasil penilitian dapat diketahui juga untuk daerah penelitian yang memiliki nilai koefisien atenuasi yang paling kecil yaitu terdapat pada titik penelitian ke-4 dengan koordinat S:-3.75265 dan E: 102.2668889 dengan nilai koefisien atenuasi sebesar $1,9 \times 10^{-3}$

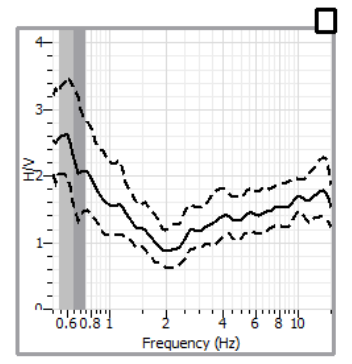

Gambar 2. Spektrum seimik lokasi penelitian 4

\section{Pemetaan Daerah Berbahaya Saat Terjadi Gempa Bumi}

Berdasarkan nilai koefisien atenuasi yang diperoleh dari 20 titik penelitian di kelurahan beringin raya dan kelurahan kandang limun, maka dengan menggunakan software ArcGIS 10.3 diperoleh peta daerah rawan kerusakan bangunan saat terjadi gempa bumi, dapat dilihat pada gambar 4.3. Untuk daerah berwarna merah dengan rentan nilai koefisien dari $1,1 \times 10^{-2}$ sampai $1,5 \times 10^{-2}$ merupakan daerah yang memiliki koefisien atenuasi tertinggi yang merupakan daerah paling rawan, warna biru dengan rentan nilai koefisien atenuasi dari $6,6 \times 10^{-3}$ sampai $1,1 \times 10^{-2}$ merupakan koefisien atenuasi sedang, warana hijau dengan rentan nilai koefisisen atenuasi dari $2 \times 10^{-3}$ sampai $6,6 \times 10^{-3}$ merupakan koefisien atenuasi kecil adalah daerah yang paling aman dari dampak bahaya gempa bumi.

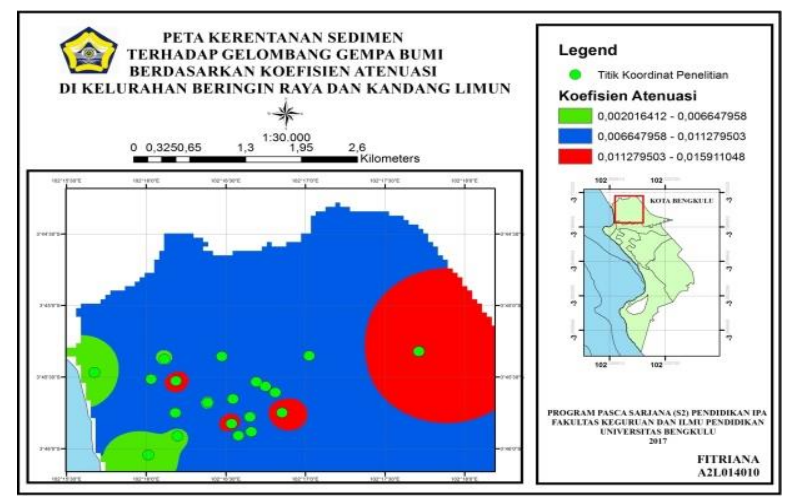

Gambar 3. Peta Daerah Rawan Saat Terjadi Gempa Bumi

\section{Kesiapsiagaan Masyarakat Terhadap Bencana Gempa Bumi}

Berdasarkan perhitungan angket yang telah dibagikan kepada masyarakat diperoleh hasil dari penelitian pendidikan/sosial masyarakat yaitu, rata-rata kesiapsiagaan masyarakat Kota Bengkulu khususnya untuk kelurahan Beringin Raya dan Kandang Limun adalah $47,14 \%$ yang berada pada kategori hampir siap. Berdasarkan kategori kesiapsiagaan masyarakat terhadap bencana gempa bumi, yang tergolong tidak siap 0\%, tergolong kurang siap $8,5 \%$, tergolong hampir siap $47,14 \%$, tergolong siap $41,43 \%$, tergolong sangat siap $2,86 \%$. Tidak ada masyarakat yang tergolong tidak siap. Berdasarkan persentase yang didapat maka 
masyarakat tergolong hampir siap untuk menghadapi ketika terjadi bencana gempa bumi.

Berdasarkan nilai Frekuensi untuk setiap kategori dapat dilihat pada diagram batang di bawah ini:

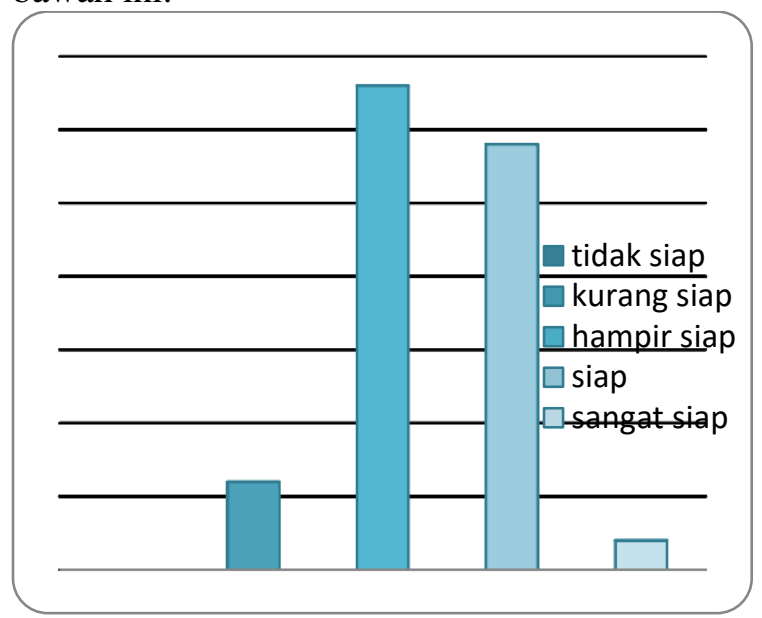

Gambar 4. Diagram frekuensi kesiapsiagaan masyarakat terhadap bencana gempa bumi

Karakter medium dapat digambarkan oleh parameter fisis seperti kecepatan dan atenuasi sesmic (Ayu, dkk. 2013). Berdasarkan analisis konsep maka daerah pada titik penelitian 12 dan 19 dinyatakan daerah yang memiliki keadaan medium yang lebih lunak dan menyebabkan perambatan gelombang akan lebih lambat, oleh karena itu saat terjadi gempa bumi daerah ini akan lebih lama merasakan getaran gelombang gempa bumi dibandingkan daerah lainnya yang memiliki nilai koefisien lebih kecil. Karena berdasarkan pada teori bahwa gelombang merambat cepat pada medium yang padat. Melalui pengamatan langsung daerah titik penelitian yang memiliki nilai koefisien yang tinggi ini merupakan daerah rawa. Oleh karena itu wajar saja kalau di titik 12 dan 19 ini memiliki nilai koefisien yang lebih tinggi.

Sedangkan untuk daerah penelitian yang memiliki nilai koefisien yang rendah yaitu pada titik penelitian ke empat. Berdasarkan konsep maka untuk daerah ini dapat dinyatakan lebih cepat perambatan gelombangnya pada saat terjadi gempa bumi, karena berdasarkan nilai koefisiennya medium pada daerah ini lebih padat dibandingkan pada derah yang lainnya. Melalui pengamatan langsung dapat dilihat bahwa daerah ini merupakan daerah dataran yang cukup tinggi dibandingkan daerah sekitarnya.
Berdasarkan data penlitian tersebut maka daerah titik penelitian keempat ini merupakan daerah yang lebih aman dari kerusakan yang terjadi akibat bencana gempa bumi.

Resiko gempa menggambarkan kemungkinan terjadinya suatu gempa dengan intensitas (percepatan, kecepatan, lama guncangan dan sebagainya) serta periode ratarata tertentu, selama masa guna bangunan di suatu tempat. Berdasarkan nilai koefisien atenuasi yang diperoleh maka diperoleh output berupa peta hasil penelitian yang menunjukan beberapa warna, yaitu warna hijau merupanakan daerah penelitian yang memiliki nilai koefisien atenuasi yang paling rendah, warna biru merupakan daerah penelitian yang memiliki koefisien atenuasi sedang, dan daerah berwarna merah merupakan daerah penelitian yang memiliki nilai koefisien atenuasi yang tinggi. Dapat dilihat bahwa ada empat titik penelitia yang berada pada zona merah, 11 titik penelitian berada pada zona biru, 5 titik penelitian berada pada zona hijau.

Berdasarkan hasil perhitungan angket yang di bagikan kepada masyarakat Kelurahan Beringin Raya dan Kelurahan Kandang Limun maka masyarakat ini dapat digolongkan pada kategori hampir siap. Sebagian masyarakat telah mendapat pelatihan atau telah mendapatkan sosialisasi dari dinas tertentu dalam menghadapi bencana gempa bumi. Namun masih ada dari beberapa masyarakat yang belum mengetahui penanggulangan bencana gempa bumi karena belum sama sekali mengikuti pelatihan simulasi atau sosialisasi yang diadakan. Oleh karena itu pada hasil penelitian ini masih sangat sedikit masyarakat yang digolongkan pada kategori sangat siap dalam menghadapi bencana gempa bumi yang sering terjadi di provinsi bengkulu ini yaitu hanya $2,86 \%$.

Sedangkan masyarakat yang tergolong pada kategori siap menjadi urutan kedua dengan persentase sebesar $41,43 \%$ hal ini dipengaruhi oleh pengetahuan masyarakat tentang bencana gempa bumi, dan yang menjadi dasar masyarakat menjadi lebih siap ketika terjadi gempa bumi yaitu kerena pengalaman yang telah sering mereka alami. Karena bagi mereka gempa bumi bukan lagi suatu fenomena langkah atau jarang terjadi seperti di daerah lain. Namun gempa bumi sudah menjadi suatu fenomena 
yang biasa bagi masyarakat yang bermukim di provinsi Bengkulu, maka hal inilah yang membuat masyarakat menjadi lebih siap dalam menghadapi bencana gempa bumi.

Namun rata-rata masyarakat di keluran Beringin Raya dan keluran Kandang Limun tergolong pada kategori hampir siap yaitu dengan persentase $47,14 \%$, karena masih banyak hal yang masih harus disiapkan oleh masyarakat dalam menghadapi bencana gempa bumi bukan hanya berdasarkan pengalaman saja tetapi pengetahuan secara teori juga sangat membantu masyarakat agar menjadi lebih siap dalam menghadapi bencana gempa bumi. Pengetahuan adalah informasi atau maklumat yang diketahui atau disadari oleh seseorang (Notoatmodjo, 2007). Jadi dengan bertambahnya pengetahuan masyarakat maka akan membuat masyarakat lebih mempersiapkan diri dan dapat meminimalisir kerugian akibat terjdi gempa bumi, khususnya pada saat masarakat akan membangun rumah, dengan pengetahuan yang dimiliki maka masyarakat dapat mempersiapkan pembangunan rumah yang bersifat tahan gempa.

\section{KESIMPULAN}

Berdasarkan hasil penelitian sains maka dapat disimpulkan bahwa dari 20 titik pengambilan data diperoleh nilai koefisien atenuasi yaitu: $4,3 \times 10^{-3} ; 8 \times 10^{-3} ; 2,1 \times 10^{-3}$; $1,9 \times 10^{-3} ; 7,4 \times 10^{-3} ; 4,3 \times 10^{-3} ; 4,5 \times 10^{-3} ; 1,4 \times 10^{-2}$; $4,7 \times 10^{-3} ; 1 \times 10^{-2} ; 1 \times 10^{-2} ; 1,6 \times 10^{-2} ; 1 \times 10^{-2} ; 1 \times 10^{-}$ 2; $1,1 \times 10^{-2} ; 1,5 \times 10^{-2} ; 1 \times 10^{-2} ; 9 \times 10^{-3} ; 1,6 \times 10^{-2}$; $1 \times 10^{-2}$. Yang tertinggi terdapat pada titik penelitiande12 dan 19 dengan titik koordinat S:3.75625 E: 102.2952222 dan S: -3.75625 E: 102.2697778 dengan nilai koefisien $1,6 \times 10^{-2}$ dan nilai terenda pada titik penelitian 4 dengan koordinat S:-3.75265 dan E: 102.2668889 dengan nilai koefisien atenuasi sebesar $1,9 \times 10^{-3}$. Peta daerah berbahaya saat terjadi gempa bumi untuk kelurahan Beringin Raya dan Kandang Limun yaitu daerah yang diberi warna merah dengan rentan nilai koefisien dari $1,1 \times 10^{-2}$ sampai $1,5 \times 10^{-2}$ merupakan daerah yang memiliki koefisien atenuasi tertinggi yang merupakan daerah paling rawan. Kesiapsiagaan masyarakat kelurahan Beringin Raya dan Kandang Limun tergolong pada kategori hampir siap dalam menghadapai bencana gempa bumi dengan persentase sebesar $47,14 \%$.

\section{DAFTAR PUSTAKA}

Arikunto, S. (2002). Dasar-dasar Evaluasi Pendidikan (Edisi Revisi). Jakarta: Rineka Cipta.

Ayu, Hena Dian dkk. (2013). Penentuan Struktur Internal Gunung Api Semeru Berdasarkan Citra Atenuasi Sesmic. Universitas Brawijaya: Bandung.

Badan Perencanaan Daerah Provinsi Jawa Barat. (2005). Rencana Induk Pengembangan Pariwisata Daerah Provinsi Jawa Barat.

Ernawati, Eva. (2011). Identifikasi Medium Penyusus Bawah Permukaan Gunung Sinabung Berdasarkan Nilai Q-Faktor. Tugas Akhir. Universitas Pendidikan Indonesia: Bandung.

Gregg, C. E., Houghton, B. F., Johnston, D. M., Paton, D., and Swanson, D. A. (2004). The Perception of Volcanic Risk in Kona Communities from Mauna Loa and Hualalai Volcanoes, Hawaiki. Journal of Volcanology and Geothermal Research, 130, 179-196.

LIPI-UNESCO/ISDR. (2006). Kajian Kesiapsiagaan Masyarakat dalam Mengantisipasi Bencana Gempa Bumi dan Tsunami.

Notoatmodjo. (2007). Definisi Pengetahuan Sikap Serta Faktor-faktor yang mempengaruhinya. Diakses tanggal 18 Desember 2016 di Http://duniabaca.com

Sengara, I.W., Hendarto, Natawidjaja, D.H., Triyoso, W., (2006), Preliminary Probabilistik Seismic Hazard analysis of sumatera for Input to Indonesia Seismic Zonation, Seminar on The active Geosphere KAGI 21 ITB Univ. Kyoto and Institut Teknologi Bandung.

Sopaheluwakan Jan, Deny Hidayati, Haryadi Permana, Krisna Pribadi, Febrin Ismail, Koen Mayers, Widayatun, Titik Handayani, Del Alfriadi Bustami, Daliyo, Fitranita, Laila Nagib, Ngadi, Yugo Kumoro, Irana Rafliana, Teti Argo, Deny. $\begin{array}{lrr}\text { (2006). } & \text { Kajian } & \text { Kesiapsiagaan } \\ \text { Masyarakat } & \text { dalam } & \text { Mengantisipasi }\end{array}$ 
Bencana Gempa Bumi \& Tsunami. Jakarta: LIPI UNESCO.

Sutton, J., and Tierney, K. (2006). Disaster Preparedness: Concepts, Guindance and Research. Colorado: University of Colorado.
Tim Penelitian LIPI - UNESCO/ISDR. (2006). Kajian Kesiapsiagaan Masyarakat Dalam Mengantisipasi Bencana Gempa Bumi \& Tsunami.

Zhai, Guofang, Fukuzono, Teruki, Ikeda, Saburo. (2005). Modelling Flood Damage case of Tokai Flood 2000. Journal of the America Water Resources Association 